\title{
EL DERECHO A LA INFORMACIÓN: BALANCE Y CUESTIONES PENDIENTES
}

DAVID ORTEGA 
SUMARIO

1. INTRODUCCIÓN. 2. DESARROLLO NORMATIVO. 2.1 Leyes que han desarrollado directamente el derecho a la información. 2.2 Leyes relacionadas indirectamente con el derecho a la información. 3. EVOLUCIÓN JURISPRUDENCIAL. 3.1 Dimensión institucional o doble carácter del derecho a la información, especialmente frente al derecho al honor. 3.2 Frente al derecho a la intimidad y a la propia imagen. 3.3 El derecho al olvido como límite al derecho a la información. 3.4 Uso de la cámara oculta. 3.5 Regulación jurídica de la radio y la televisión. 3.6 Cláusula de conciencia. 3.7 Derecho de rectificación. 3.8 Veracidad informativa y relevancia pública de la noticia. 3.9 Especial referencia al TEDH. 4. DEONTOLOGÍA PERIODÍSTICA Y MECANISMOS DE AUTORREGULACIÓN. 5. CONCLUSIONES Y CUESTIONES PENDIENTES. 


\title{
EL DERECHO A LA INFORMACIÓN: BALANCE Y CUESTIONES PENDIENTES
}

\author{
DAVID ORTEGA ${ }^{1}$
}

\section{INTRODUCCIÓN}

Es buena ocasión, las cuatro décadas de vida de nuestro Texto constitucional, para hacer balance de la evolución y los temas pendientes de su parte dogmática y, más concretamente, del derecho a la información que el poder constituyente reguló en el artículo 20.1.d) CE. Analizaremos en primer lugar el desarrollo normativo que este derecho ha tenido en estos años. Para ello, dividiremos las normas jurídicas en dos bloques. En el primero veremos aquéllas que desarrollan de manera directa el derecho a la información para estudiar, en el segundo, las distintas leyes que no desarrollan directamente el derecho a la información, pero que sí inciden en el mismo básicamente por limitarle o contribuir, de una u otra forma, a perfilar su contenido.

En un segundo apartado abordaremos el estudio de las principales aportaciones realizadas por la extensa jurisprudencia del Tribunal Constitucional sobre la materia, incluyendo también una referencia, aunque necesariamente breve, a la influyente doctrina desarrollada por el Tribunal Europeo de Derechos Humanos. En tercer lugar, por la influencia que tiene en la práctica del derecho a la información, apuntaremos las medidas de autorregulación más destacadas que se han dado en estos años. Terminaremos este trabajo realizando una valoración y balance global sobre el derecho a la información y las diferentes cuestiones que estimamos faltan por afrontarse.

1 Catedrático de Derecho Constitucional de la Universidad Rey Juan Carlos. Edif. Rectorado, Calle Tulipán, s/n, 28933 Móstoles, Madrid david.ortega@urjc.es 


\section{DESARROLLO NORMATIVO}

En este apartado destacaremos aquellas leyes que de forma directa o indirecta han incidido o influido en el desarrollo y evolución del derecho a la información. De manera colateral, en algunos casos relevantes, indicaremos la normativa comunitaria que también haya marcado la evolución normativa. Seguiremos principalmente un criterio cronológico que nos permita ir viendo la evolución de la labor de nuestro Legislador a lo largo de todos estos años. Como ya hemos indicado, dividiremos este apartado en dos epígrafes, en el primero veremos las leyes que han desarrollado directamente el derecho a la información; en el segundo apuntaremos aquéllas que lo han hecho de manera indirecta o colateral.

\subsection{Leyes que han desarrollado directamente el derecho a la información}

En este epígrafe estudiaremos aquellas leyes que ha aprobado nuestro Legislador en estas cuatro décadas como desarrollo directo e inmediato del artículo 20.1.d) CE. En la década de los ochenta destaca como norma jurídica principal que impulsa el derecho a la información la Ley Orgánica 2/1984, de 26 de marzo, reguladora del Derecho de Rectificación. Esta Ley, que lógicamente al tratar una materia que incide directamente en el derecho a la información del artículo 20.1.d) debe tener rango de ley orgánica (art. 81.1 CE), viene a actualizar, ya en democracia, el artículo 58 que contemplaba el derecho de réplica de la semiderogada Ley 14/1966, de Prensa e Imprenta.

Desde la normativa comunitaria, fueron importantes en esta materia del derecho a la rectificación, tanto la conocida Directiva de la Televisión sin Fronteras $^{2}$, como la Directiva 97/36/CE, del Parlamento Europeo y Consejo, de 30 de junio, que la modifica y actualiza. La LO 2/1984 se aprobó en el Parlamento español sin grandes problemas o disensiones, salvo el objeto que determina el artículo 2.2 cuando indica que «la rectificación deberá limitarse a los hechos de la información que se desea rectificar». En el Dictamen de la Comisión de Justicia e Interior del Congreso de los Diputados sí se pretendía incluir además de los hechos, el contenido y la opinión que pudieran acompañar a los hechos, lo que era una absoluta barbaridad y lógicamente, tras una importante polémica, no prospero.

Para concluir con el estudio de esta Ley, cuyo funcionamiento ha sido más que correcto y ya cuenta con una vida extensa, sí debemos señalar que ha precisado de alguna concreción y aclaración de nuestro Tribunal Constitucional, como

${ }^{2}$ Directiva 89/552/CEE, de 3 de octubre. 
las SSTC 168/1986, de 22 de diciembre; 240/1992, de 21 de diciembre; 51/2007, de 12 de marzo, del entonces ministro del PP, Álvarez-Cascos contra la Cadena Ser o la más reciente 99/2011, de 20 de junio. También hay que tener presente alguna sentencia, incluso anterior a la propia Ley, como la 35/1983, de 11 de mayo. Parte de ellas las estudiaremos más adelante ${ }^{3}$.

En la década de los noventa tenemos la escueta Ley Orgánica 2/1997, de 19 de junio, reguladora de la cláusula de conciencia de los profesionales de la información. Indicar que el Legislador cumplía después de 19 años y múltiples proposiciones de ley, especialmente de los grupos parlamentarios del CDS y de IU, con el mandato que el propio constituyente estableció en el art. 20.1.d) en los siguientes términos: «La ley regulará el derecho a la cláusula de conciencia y al secreto profesional en el ejercicio de estas libertades». Destaca el especial interés que se tomaron nuestros constituyentes por proteger el ejercicio de los profesionales de la información. No es frecuente en un texto constitucional que se llegue a tanto detalle.

Respecto de esta Ley señalar que se perdió una buena oportunidad para regular legalmente quién es periodista en España, algo que sí hacían las proposiciones de ley frustradas de los grupos parlamentarios citados. La cuestión tiene su interés, pues así se hubiera aclarado por vía legal los sujetos que legítimamente pueden disfrutar de ambos derechos. En cualquier caso, es comúnmente admitido que pueden ejercer estos derechos aquellos profesionales de la información cuya actividad principal y remunerada sea realizar labores propias y específicas de los periodistas como obtener, elaborar y difundir información. Por lo demás, queda pendiente —y la conmemoración de los 40 años de nuestra Constitución pudiera ser un buen momento-, que el Legislador español elabore la correspondiente ley orgánica sobre el secreto profesional ${ }^{4}$.

En la primera década del siglo xxi destaca con peso propio la Ley 17/2006, de 5 de junio, de la radio y la televisión de titularidad estatal. Es una Ley importante para la regulación de la radio y especialmente de la televisión pública. Se mantiene el criterio adoptado por el Gobierno Suárez (UCD) en la Ley 4/1980, de 10 de enero, Estatuto Básico de la Radio y Televisión, de mantener la titularidad pública de la radio y la televisión en España. Es una decisión política que la Constitución deja al Parlamento correspondiente. Al día de hoy, todos los Gobiernos lo han seguido con el apoyo del artículo 128.2 CE: «[...] Mediante ley se podrá reservar al sector

3 Infra, apartado 3. Evolución jurisprudencial.

${ }^{4}$ Como indicábamos con anterioridad, no han faltado diferentes proposiciones de ley al respecto, especialmente de los grupos parlamentarios del CDS: Proposiciones de Ley de 28 de julio de 1986 y de 21 de abril de 1988; y de IU: Proposiciones de Ley de 18 de noviembre de 1988, y junto con Iniciativa per Catalunya, de 30 de noviembre de 1989 y 14 de septiembre de 1993. 
público recursos o servicios esenciales [...]». Tanto el Estatuto de 1980 como la Ley del 2006 mantienen el carácter público y estatal de los servicios de radio y televisión, bien es verdad que cabe la gestión privada del servicio a través de la correspondiente concesión, siendo siempre la titularidad del Estado.

Es eterna la cuestión de la politización de la televisión pública, desde sus inicios hasta hoy, ha sido y es un tema recurrente. Es verdad que la Ley 17/2006 intentó y logró una mayor autonomía política a la hora de elegir a los miembros del Consejo de Administración de la Corporación de RTVE y a su Presidente. Sin embargo, el primer Gobierno de Rajoy (PP) aprovechó su mayoría absoluta para modificar el artículo 11 de la Ley y rebajar la mayoría cualificada de dos tercios, para elegir a los miembros del Consejo de Administración y a su Presidente, a mayoría absoluta ${ }^{5}$. Por tanto, solo dependía de sí mismo para sacar a sus candidatos. Sin embargo, en la presente Legislatura, no goza ya el PP de esa mayoría, y parece en este momento que diferentes grupos parlamentarios, a mi entender con buen criterio, pretenden volver a los principios de consenso y pluralidad de la regulación inicial del artículo 11 del año 2006.

Ciertamente en materia televisiva la regulación ha sido más bien dispersa, sin mucho criterio y finalidades claras, ha faltado un modelo consensuado y ambicioso de una prestigiosa e independiente televisión pública, y a lo largo de estas décadas hemos asistido a un excesivo y prolijo baile normativo de diferentes leyes que regulaban diversos ámbitos y distintos soportes de difusión y emisión en materia televisiva y de telecomunicaciones. Hemos visto nacer y desaparecer una docena de leyes en relación con la televisión y las telecomunicaciones: Ley 4/1980, de 10 de enero, del Estatuto Básico de la Radio y la Televisión; Ley 46/1983, de 26 de diciembre, reguladora del Tercer Canal de Televisión; Ley 31/1987, de 18 de diciembre, de Ordenación de las Telecomunicaciones; Ley 10/1988, de 3 de mayo, de Televisión Privada; Ley 25/1994, de 12 de julio, que incorpora la Directiva 89/552/CEE; diciembre del año 1995 fue especialmente prolijo con la Ley 37/1995, de 12 de diciembre, reguladora de las Telecomunicaciones por Satélite ${ }^{6}$; Ley 41/1995, de 22 de diciembre, de Televisión Local por Ondas Terrestres; Ley 42/1995, de 22 de diciembre, de Telecomunicaciones por Cable; Ley 11/1998, de 24 de abril, General de Telecomunicaciones; Ley 32/2003, de 3 de noviembre, General de Telecomunicaciones; Ley 10/2005, de 14 de junio, de medidas urgentes para el impulso de la televisión digital terrestre, de liberalización de la televi-

5 Ver Real Decreto-ley 15/2012, de 20 de abril.

6 Única Ley que hasta la fecha no ha contemplado el carácter público de este servicio. Así, su artículo 1.1 señalaba que «los servicios de telecomunicaciones para cuya prestación se utilicen de forma principal redes de satélites de comunicaciones no tendrán la consideración de servicio público». 
sión por cable y de fomento del pluralismo y Ley 7/2009, de 3 de julio, de medidas urgentes en materia de Telecomunicaciones.

Dentro de las Leyes relevantes que están en vigor, por el momento, destacan, junto con la ya mencionada Ley 17/2006:

A) la Ley 7/2010, de 31 de marzo, General de la Comunicación Audiovisual, en cuyo Título V se regulaba el Consejo Estatal de Medios Audiovisuales, de vida breve, pues la Ley 3/2013, de 4 de junio, deroga el citado Título y la labor del suprimido Consejo Estatal pasa a desarrollarla la Comisión Nacional de los Mercados y la Competencia (CNMC). La CNMC cuenta con una Dirección de Telecomunicaciones y del Sector Audiovisual ${ }^{7}$, que es la que se encarga de regular, supervisar y controlar el correcto funcionamiento del mercado de la comunicación audiovisual, además de la instrucción de los expedientes sancionadores ${ }^{8}$, en su caso.

Consejos de Medios Audiovisuales similares a nivel autonómico se dieron en algunas Comunidades Autónomas como Cataluña, Navarra, Andalucía, Madrid y Galicia. Actualmente solo siguen en funcionamiento los de Cataluña y Andalucía. La clave para que estos órganos puedan cumplir con eficacia sus cometidos está en su independencia frente al Gobierno y al corporativismo de las grandes cadenas y que, además, sean una auténtica y plural representación de la sociedad civil. Para ello deberían: 1. Tener personalidad jurídica propia. 2. Composición plural. 3. Estar formados por expertos profesionales y 4. Evitar el control de los políticos y de los intereses comerciales del sector. Es también importante que estos Consejos Audiovisuales tengan especial sensibilidad en la protección de los grupos más desprotegidos como los menores, personas con disfuncionalidad o los inmigrantes. Por lo demás, hace pocos meses el Tribunal Constitucional ha declarado inconstitucionales algunos artículos de la Ley 22/2005, de 29 de diciembre, de la comunicación audiovisual de Cataluña9 .

7 Está regulada por la propia Ley 3/2013, de 4 de junio, además de por la Ley 7/2010, de 31 de marzo y la actual Ley General de las Telecomunicaciones, de 9 de mayo de 2014.

8 Por citar un ejemplo, el 6 de abril de 2016 se sanciona a Mediaset por el programa «Sálvame Naranja» de 9 de junio de 2015, por emitir contenidos perjudiciales para el desarrollo físico, mental y moral de los menores. Resolución del Consejo de 1 de marzo de 2016. Multa de 196.001 euros. Canal Tele 5, franja no recomendable a menores de 7 años. Infracción grave. Artículo 7.2 Ley $7 / 2010$.

9 Ver STC 78/2017 de 22 de junio, que resuelve recurso de inconstitucionalidad interpuesto por el Presidente del Gobierno. En la misma se establece la nulidad de los preceptos legales autonómicos que desconocen la competencia exclusiva del Estado para la planificación del espacio radioeléctrico, contradicen la normativa básica estatal en materia de licencias para servicios de comunicación audiovisual cuya prestación exige el uso del espectro radioeléctrico y atribuyen a las instituciones autonómicas determinadas competencias de inspección, control y sanción. 
B) la, por el momento, última Ley en materia de Telecomunicaciones, la Ley 9/2014, de 9 de marzo, General de Telecomunicaciones. Tal y como nos indica su propio Preámbulo: «introduce reformas estructurales en el régimen jurídico de las telecomunicaciones dirigidas a facilitar el despliegue de redes y la prestación de servicios por parte de los operadores, para que ello les permita ofrecer a los usuarios servicios más innovadores, de mayor calidad y cobertura, a precios más competitivos y con mejores condiciones, lo que contribuirá a potenciar la competitividad y la productividad de la economía española en su conjunto. También favorece la seguridad jurídica, al compendiar la normativa vigente, y en particular en lo que se refiere al marco comunitario de las comunicaciones electrónicas».

Para concluir el análisis de la evolución y desarrollo normativo del derecho a la información, debemos hacer una mención especial a la Ley 19/2013, de 9 de diciembre, de transparencia, acceso a la información pública y buen gobierno ${ }^{10}$. Lo primero que debemos señalar es que llegó demasiado tarde, tratándose de una materia tan importante como la transparencia y la consecuente lucha contra la corrupción. Esta tardanza se reconoce en el propio Preámbulo (apartado II) de la Ley: «España no podía permanecer por más tiempo al margen». Fuimos de los últimos países, sino el último de la UE, en aprobar una Ley de transparencia, acceso a la información pública y buen gobierno ${ }^{11}$. Por lo demás, como comentario global, es casi unánime la opinión de la falta de ambición del Legislador para avanzar más y mejor en esta materia, como muestran, por citar dos ejemplos, el elevado número de límites que se ponen al derecho de acceso a la información pública y lo excesivamente complejo y disuasorio del procedimiento de acceso, en contraste con otros países de nuestro entorno.

Destacar, respecto de la tramitación parlamentaria, que los grupos parlamentarios de UPyD e IU plantearon sendas enmiendas a la totalidad, básicamente centradas en que dada la relevancia de la materia que se trataba, debiera de haberse tramitado como ley orgánica. La cuestión en sí misma es más que relevante, pues como argumentaban ambos grupos parlamentarios ${ }^{12}$, el derecho de

10 Sobre la misma ver, Gabriel Moreno González, «El derecho de acceso a la información pública en la Ley de transparencia: una aproximación constitucional», en Eunomia. Revista en Cultura de la Legalidad, n. ${ }^{\circ}$ 8, marzo-agosto 2015, pp. 93-125; Lorenzo Cotino Hueso, «La nueva Ley de Transparencia y acceso a la información», en Anuario Facultad de Derecho-Universidad de Alcalá VII, 2014, pp. 241-256.

11 Para un estudio comparativo internacional en la materia, ver Manuel Arenilla Sáez, Estudio comparado sobre normativa internacional en materia de derecho de acceso a la información pública, Madrid, INAP, 2016.

12 Ver http://www.congreso.es/public_oficiales/L10/CONG/BOCG/A/BOCG-10-A-19-3. PDF enmienda n. ${ }^{\circ} 34$, p. 17 ss. y enmienda n. ${ }^{\circ} 74$, p. 24 ss., respectivamente. 
acceso a la información pública se entiende como un «derecho básico o fundamental» y ello implica, conforme al artículo 81.1 CE, que se desarrolle como ley orgánica. No lo consideró así el Gobierno, que en vez de entender el derecho de acceso a la información pública como parte del contenido del artículo 20.1.d) CE, como proponían con buen criterio UPyD e IU, lo hace depender del desarrollo —según el artículo 12 de la propia Ley_ del artículo 105.b) CE. A nuestro entender, es un mal comienzo de esta Ley no considerar el derecho de acceso a la información pública como un derecho fundamental de la sección 1 . $^{\text {a }}$ del Capítulo 2. ${ }^{\circ}$ del Título primero de nuestra Constitución, con todas las garantías que esto implica, marginándolo al Título IV.

La cuestión desde luego no ha pasado desapercibida para la doctrina. Así, el 10 de diciembre de 2016, justo dos años después de la entrada en vigor de la Ley, cerca de medio centenar de especialistas en derecho a la información y derechos fundamentales ${ }^{13}$, firmaron un manifiesto promovido por Access Info Europe $^{14}$, solicitando al Gobierno y a los poderes públicos que consideren al derecho de acceso a la información pública como un derecho fundamental.

Los argumentos del manifiesto eran ciertamente sólidos, se explicaba como la legislación española se situaba «en contra de la tendencia general del Derecho internacional y europeo y contraviene el mandato del artículo 10.2 de la Constitución, que establece que las normas relativas a los derechos fundamentales y a las libertades que la Constitución reconoce se interpretarán de conformidad con la Declaración Universal de Derechos Humanos y los tratados y acuerdos internacionales sobre las mismas materias ratificados por España. En efecto, los artículos 19 de la Declaración Universal de Derechos Humanos, 19 del Pacto Internacional de Derechos Civiles y Políticos, y 10 del Convenio Europeo de Derechos Humanos, se entienden inclusivos del derecho de acceso a la información pública. Igualmente se reconoce como derecho fundamental en los artículos 11 y 42 de la Carta de los Derechos Fundamentales de la Unión Europea y ha sido reconocido como tal por el Tribunal Europeo de Derechos Humanos».

Junto a estos argumentos ${ }^{15}$, se pueden añadir algunas conocidas sentencias del ámbito de los tribunales internacionales en materia de protección de los derechos fundamentales, que estiman el carácter de «fundamental» del derecho de acceso a la información pública. La primera de ellas es la Sentencia de 19 de

13 Tuve el honor de estar entre los colaboradores en la redacción, promoción y firma del mismo.

14 https://www.access-info.org/es/frontpage-es/27052

15 Sobre la cuestión, más extensamente, ver Göran Rollnert Liern, «El derecho de acceso a la información pública como derecho fundamental: una valoración del debate doctrinal a propósito

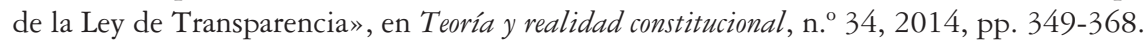


septiembre de 2006 de la Corte Interamericana de Derechos Humanos, caso Claude Reyes y otros versus Chile ${ }^{16}$. Tres años después es el TEDH el que interpreta el artículo 10 del Convenio Europeo para la protección de los derechos fundamentales y libertades públicas en términos parecidos en varias sentencias, destacando la Sentencia de 16 de agosto de 2009, caso Kennedy versus Hungría. Incluso el propio Comité de Derechos Humanos de Naciones Unidas asume en el año 2011 esta doctrina de los citados tribunales internacionales.

Sin embargo, lamentablemente, tanto nuestro Legislador como el propio Tribunal Constitucional, no consideran el derecho de acceso a la información como parte del contenido del artículo 20.1.d) CE - lo que sería en nuestra opinión y en la que mantienen los tribunales internacionales, lo más adecuado-, sino como desarrollo del artículo 105.b) CE. Por ello es ley ordinaria la Ley 19/2013 y el Tribunal Constitucional en dos ocasiones ha desestimado sendos recursos de amparo.

Curiosamente, los grupos parlamentarios de CiU y PNV iban a presentar también sus respectivas enmiendas a la totalidad, pero su postura negativa se tornó en apoyo cuando el Ejecutivo se comprometió a respetar las competencias autonómicas en la materia ${ }^{17}$.

Por lo tanto, la Ley sí supone un avance, pero se ha quedado a mitad de camino, perdiendo una buena oportunidad de tener mejores herramientas para afrontar uno de los principales problemas de nuestra vida pública y política: el exceso de corrupción. Lógicamente nos hemos referido al acceso a la información pública de las instituciones españolas. El acceso a la información de las instituciones europeas, al cual también tenemos derecho, va más allá del objeto de este artículo $^{18}$.

Respecto de su aplicación, sí debemos indicar la buena labor realizada por el Consejo de Transparencia y Buen Gobierno, a pesar de que en principio, pudiera dudarse de su independencia del Gobierno ${ }^{19}$. La labor de denuncia en estos primeros años de funcionamiento de la Ley, por parte del Consejo de Transpa-

\footnotetext{
${ }^{16}$ http://www.corteidh.or.cr/cf/Jurisprudencia2/ficha_tecnica.cfm?nId_Ficha=332\&lang=e

17 http://www.infolibre.es/noticias/politica/2013/05/30/el_gobierno_rechazara_las_enmiendas_totalidad_ley_transparencia_4226_1012.html

18 En cualquier caso, se puede consultar el interesante trabajo de José María Porras RamíREZ, «Los límites a la transparencia. El menguado alcance del derecho de los ciudadanos a acceder a la información en poder de las instituciones europeas», en Teoría y realidad constitucional, n. 33 , 2014, pp. 283-304.

19 Según el artículo 37.1 de la Ley, su Presidente es elegido por mayoría absoluta del Congreso de los Diputados a propuesta del Ministerio de Hacienda y Administraciones Públicas. La primera Presidente/a del Consejo es Esther Arizmendi.
} 
rencia, no está siendo menor, especialmente frente al Gobierno y otros entes públicos. Así, organismos como RTVE, la Fábrica Nacional de Moneda y Timbre, la empresa pública Tragsa y el propio Gobierno de España, no están siendo buenos ejemplos de colaboración y respeto a la Ley, según, insistimos, el propio Consejo de Transparencia ${ }^{20}$. En abril de 2017 el Consejo publica su primer ranking oficial de transparencia de los órganos constitucionales y entes reguladores $^{21}$. Respecto del cumplimiento de la transparencia obligatoria, destacan en los primeros puestos el Tribunal Constitucional $(9,83)$ y el Consejo General del Poder Judicial $(9,70)$, que rozan el 10. Por el contrario, necesitan mejorar considerablemente en materia de transparencia la Fiscalía General del Estado $(5,66)$ y el Consejo Económico y Social $(5,4)$, que aprueban sin demasiada holgura ${ }^{22}$.

\subsection{Leyes relacionadas indirectamente con el derecho a la información}

En este epígrafe incluiremos aquellas leyes que, sin haber desarrollado de manera directa el derecho a la información, como las que acabamos de analizar en el epígrafe anterior, han influido en alguna manera en el desarrollo y concreción del mismo, básicamente en el terreno de los límites.

Conviene indicar, en relación con aquellas leyes franquistas que aún hoy siguen estando en vigor, aunque sea parcialmente, que junto con la conocida y citada Ley de Prensa e Imprenta de 1966 — que afecta directamente a nuestra materia objeto de estudio en aquellos pocos artículos que hoy siguen en vigor-, también tenemos la Ley 9/1968, de 5 de abril, de Secretos Oficiales, que sin ser una ley de desarrollo directo del derecho a la información, sí figura como un límite al ejercicio del mismo, tal y como contempla el artículo 105.b) de la Constitución ${ }^{23}$. Bien es verdad que esta Ley fue modificada y adaptada ya en democracia,

${ }^{20}$ http://politica.elpais.com/politica/2016/02/05/actualidad/1454706194_906498.html En el artículo se destaca que el Gobierno recurre a los Tribunales para evitar responder sobre transparencia, concretamente se apuntan cinco recursos para oponerse al criterio del Consejo de Transparencia que el propio Gobierno impulsó.

21 Estos órganos son: Casa de S. M. El Rey, Congreso de los Diputados, Senado, Tribunal Constitucional, Consejo General del Poder Judicial, Banco de España, Consejo Económico y Social, Comisión Nacional de los Mercados y la Competencia, Comisión del Mercado de Valores, Tribunal de Cuentas, Defensor del Pueblo, Consejo de Estado, Autoridad Independiente de Responsabilidad Fiscal, Consejo de Seguridad Nuclear y Fiscalía General del Estado.

${ }^{22}$ Ver Informe 1707 de marzo de 2017. http://consejodetransparencia.buscador.gob.es/sear ch? proxystylesheet $=$ ctransp\&site $=$ CTRANSP_ES.

23 El mismo señala que «La ley regulará: b) el acceso de los ciudadanos a los archivos y registros administrativos, salvo en lo que afecte a la seguridad y defensa del Estado, la averiguación de 
aunque preconstitucional, con la Ley 48/1978, de 7 de octubre. No siempre es fácil el equilibrio entre el acceso a la información y la seguridad nacional que protege esta Ley ${ }^{24}$.

Más importante e influyente, sin ninguna duda, como límite al ejercicio del derecho a la información, es la Ley Orgánica 1/1982, de 5 de mayo, de Protección Civil del Derecho al Honor, a la Intimidad Personal y Familiar y a la Propia Imagen. Como es bien conocido, los principales conflictos con los derechos regulados en el artículo 20.1 CE se encuentran en los derechos del artículo $18 \mathrm{CE}$, primordialmente con los tres regulados en su apartado primero: el derecho al honor, a la intimidad personal y familiar y a la propia imagen. Es una Ley que tiene ya una larga vida y que ha sido modificada y actualizada en múltiples ocasiones. Probablemente su artículo más relevante e influyente sea el séptimo, que contempla lo que se consideran intromisiones ilegítimas. No deja de ser curioso que la Ley regule de manera conjunta los tres derechos que incluye el artículo $18.1 \mathrm{CE}$, a pesar de que la jurisprudencia del Tribunal Constitucional los considera derechos autónomos e independientes ${ }^{25}$. Al respecto la doctrina mantiene diferentes posturas $^{26}$.

Sin abandonar el artículo 18, que es un claro límite al artículo 20.1. CE, tal y como nos indica el propio artículo 20 en su apartado cuarto, tenemos que detenernos brevemente en su apartado también cuarto, que regula el denominado derecho al habeas data. Dice así: «La ley limitará el uso de la informática para garantizar el honor y la intimidad personal y familiar de los ciudadanos y el pleno ejercicio de sus derechos». Esta Ley es la Ley Orgánica 15/1999, de 13 de diciembre, de protección de datos de carácter personal. Su artículo 5.1 regula el derecho

los delitos y la intimidad de las personas». Lógicamente la Ley de Secretos Oficiales regula el primer límite que indica la Constitución.

${ }^{24} \mathrm{Al}$ respecto ver Rosario Serra Cristóbal, «La opinión pública ante la vigilancia masiva de datos. El difícil equilibrio entre el acceso a la información y la seguridad nacional», en Revista de Derecho Político, n. ${ }^{\circ}$ 92, enero-abril 2015, pp. 73-118.

${ }^{25}$ En este sentido la STC 83/2002 establece que: «los derechos fundamentales consagrados en el artículo 18.1 de la Constitución [...], tienen un contenido propio y específico. Dado, pues, que son derechos autónomos, debemos enjuiciar por separado las vulneraciones aducidas». En una línea similar, ver SSTC 81 y 156/2001, fundamentos jurídicos $2 .^{\circ}$ y $3 .^{\circ}$, respectivamente. Más recientemente, STC 12/2012, de 30 de enero, fundamento jurídico $5 .^{\circ}$

26 Álvarez Conde indica que «A este respecto, las posturas doctrinales van desde afirmar que el bien jurídicamente protegido es el derecho a la intimidad, siendo los otros dos una concreción de éste, hasta las que señalan que el derecho al honor tiene sustantividad propia, a diferencia del derecho a la intimidad, del cual sí que debe considerarse como una auténtica manifestación del derecho a la propia imagen. Quizás la solución consista en proclamar la sustantividad propia de cada uno de estos derechos fundamentales». Ver Enrique Álvarez Conde, Curso de Derecho Constitucional, vol. I, Madrid, Tecnos, 2003, p.369. 
a la información en la recogida de datos. Jurisprudencialmente sus artículos originales 21.1 y 24.1 son modificados por la STC 292/2000, de 30 de noviembre $^{27}$. La Ley es resultado principalmente de la Directiva 95/436/CE, Reglamento General de Protección de Datos. Esta materia se ha actualizado en la Unión Europea con el Reglamento 2016/679 del Parlamento Europeo y del Consejo, de 27 de abril de $2016^{28}$.

Por último, debemos citar la polémica Ley Orgánica 4/2015, de 30 de marzo, de protección de la seguridad ciudadana ${ }^{29}$. Según su artículo 36, que regula las infracciones graves, en el apartado 23 nos indica: «El uso no autorizado de imágenes o datos personales o profesionales de autoridades o miembros de las Fuerzas y Cuerpos de Seguridad que pueda poner en peligro la seguridad personal o familiar de los agentes, de las instalaciones protegidas o en riesgo el éxito de una operación, con respeto al derecho fundamental a la información». El mismo puede convertirse en un claro límite al derecho a la información. La cuestión, no fácil de dilucidar, consiste en valorar cuándo unas imágenes pueden poner en peligro la seguridad personal de un agente o de sus familiares. Por lo demás, los abusos policiales en bastantes ocasiones se han podido demostrar gracias, precisamente, a poder fotografiar a los miembros de los Cuerpos y Fuerzas de seguridad del Estado en acción, como en su día denunció Amnistía Internacional ${ }^{30}$.

\section{EVOLUCIÓN JURISPRUDENCIAL}

No ha sido menor la labor realizada por el Tribunal Constitucional a la hora de interpretar y perfilar el contenido del derecho a la información. Debemos destacar que después del artículo 14 CE y el artículo 24, es el artículo 20.1.d) el que más recursos de amparo ha producido, principalmente por sus tensiones con el derecho al honor y, en menor medida, con los derechos a la intimidad y a la propia imagen. Por tanto, han sido muchas las sentencias sobre la materia ${ }^{31}$.

27 Destaca especialmente su fundamento jurídico 5. ${ }^{\circ}$ La Sentencia es fruto de un recurso de inconstitucionalidad interpuesto por el Defensor del Pueblo.

28 Entró en vigor el 25 de mayo de 2016, pero no se aplicará hasta el 25 de mayo de 2018, hasta entonces se sigue aplicando la citada Directiva del año 1995.

29 Más conocida con el coloquial nombre de Ley Mordaza, fue aprobada en solitario con la mayoría absoluta del Gobierno del PP de Mariano Rajoy.

30 Amnistía Internacional: «Captar imágenes de la policía, ya lo hicieran periodistas u otras personas con cámaras o teléfonos móviles, ha ayudado en ocasiones a difundir información sobre el uso excesivo de la fuerza por parte de la policía». Ver El País de 1 de julio de 2015.

31 Ver Eduardo Francisco Rodríguez Gómez, «El Tribunal Constitucional y el conflicto entre la libertad de información y los derechos al honor, la intimidad y la propia imagen: revisión juris- 
Evidentemente, en este trabajo, tan solo podremos destacar las más relevantes ${ }^{32}$. Las expondremos siguiendo un criterio de contenidos en relación con el derecho a la información.

\subsection{Dimensión institucional o doble carácter del derecho a la información, especialmente frente al derecho al honor}

La relevancia especial que tiene el derecho a la información para la formación de una sociedad democrática y su importancia para el ejercicio de otros derechos, ya la encontramos en la temprana STC 6/1981, de 16 de marzo, especialmente en su fundamento jurídico $3 .^{\circ}$ : «El art. 20 de la Constitución, en sus distintos apartados, garantiza el mantenimiento de una comunicación pública libre, sin la cual quedarían vaciados de contenido real otros derechos que la Constitución consagra, reducidas a formas hueras las instituciones representativas y absolutamente falseado el principio de legitimidad democrática que enuncia el artículo 1.2 de la Constitución, y que es la base de toda nuestra ordenación jurídico-política. La preservación de esta comunicación pública libre sin la cual no hay sociedad libre ni, por tanto, soberanía popular, exige la garantía de ciertos derechos fundamentales comunes a todos los ciudadanos, y la interdicción con carácter general de determinadas actuaciones del poder (verbi gratia las prohibidas en los apartados 2 y 5 del mismo art. 20), pero también una especial consideración a los medios que aseguran la comunicación social y, en razón de ello, a quienes profesionalmente los sirven».

La STC 104/1986, de 17 de julio, caso Soria Semanal, es otra de las más conocidas. En base a la ya citada STC 6/1981, el Tribunal Constitucional da un paso más allá y apunta la prevalencia o preferencia del derecho a la libre expresión y a la no menos libre información [art. 20.1.a) y d)] sobre los derechos personalísimos del artículo 18.1 CE. Lo más determinante lo encontramos en el segundo párrafo del fundamento jurídico 5..$^{\circ}$, que nos define el doble carácter o dimensión institucional de estos derechos de libertad informativa: «Esta dimensión de garantía de una institución pública fundamental, la opinión pública libre, no se

prudencial», en Estudios sobre el mensaje periodístico, vol. 20, n. 2 (2014), pp. 1209-1224. En la página 1215 ofrece el dato de que entre los años 1982 a 2013 se dieron 105 resoluciones —entre sentencias y autos - del Tribunal Constitucional sobre la materia. En 40 ocasiones se amparó el derecho a la información, en 65 el recurso fue inadmitido.

32 De manera más exhaustiva, ver María Acracia Núñez Martínez, «El Tribunal Constitucional y las libertades del artículo 20 de la Constitución española», en Revista de Derecho, UNED, n. ${ }^{\circ}$ 3, 2008, pp. 289-317. 
da en el derecho al honor; o, dicho con otras palabras, el hecho de que el art. 20 de la Constitución «garantiza el mantenimiento de una comunicación pública libre sin la cual quedarían vaciados de contenido real otros derechos que la Constitución consagra, reducidas a formas hueras las instituciones representativas y absolutamente falseado el principio de legitimidad democrática» (Sentencia del Tribunal Constitucional 6/1981, de 16 de marzo), otorga a las libertades del artículo 20 una valoración que trasciende a la que es común y propia de todos los derechos fundamentales». Hasta esta Sentencia del año 1986, prácticamente cualquier intromisión en el ámbito del contenido de los derechos personalísimos del artículo 18.1 CE era considerada inconstitucional. Pero a partir de ella y, como ahora veremos, aunque no se cite por el Tribunal Constitucional, se pasa un modelo de ponderación marcado pocos días antes por el TEDH.

Como acabamos de apuntar, tenemos que esperar a la STC 107/1988, de 8 de junio, para encontrar incorporada explícitamente a la jurisprudencia del Tribunal Constitucional, la importante Sentencia Lingens, del Tribunal Europeo de Derechos Humanos, de 8 de julio de 1986, tal y como vemos en el último párrafo del fundamento jurídico $1 .^{\circ}:$ «Por consiguiente, se plantea en este recurso un problema de conflicto entre la libertad de expresión, reconocida en el artículo 20.1.a) de la Constitución, y el derecho al honor, protegido por el artículo 18.1 de la misma Norma fundamental. Su solución, obviamente, debe obtenerse de conformidad con la doctrina constitucional establecida, entre otras, en las SSTC 51/1985, de 10 de abril; 104/1986, de 17 de julio; 165/1987, de 27 de octubre, y 6/1988, de 21 de enero, teniendo también presente la jurisprudencia del TEDH, en la que destaca con especial relieve la Sentencia del caso Lingens de 8 de julio de 1986. 2. El reconocimiento constitucional de las libertades de expresión y de comunicar y recibir información ha modificado profundamente la problemática de los delitos contra el honor en aquellos supuestos en que la acción que infiere en este derecho lesión penalmente sancionable haya sido realizada en ejercicio de dichas libertades, pues en tales supuestos se produce un conflicto entre derechos fundamentales, cuya dimensión constitucional convierte en insuficiente el criterio subjetivo del animus injuriandi, tradicionalmente utilizado por la jurisprudencia penal en el enjuiciamiento de dicha clase de delitos, pues este criterio se ha asentado hasta ahora en la convicción de la prevalencia absoluta del derecho al honor» ${ }^{33}$.

33 Será pues esta Sentencia, la que cierre y consolide la jurisprudencia iniciada por nuestro más alto Tribunal con la STC 6/1981. 


\subsection{Frente al derecho a la intimidad y a la propia imagen}

No debemos olvidar que el doble carácter o dimensión institucional del derecho a la información — también del derecho a la libertad de expresión- se aplica por parte de nuestro Tribunal Constitucional frente a los derechos personalísimos recogidos en el artículo 18.1 CE y muy especialmente frente al derecho al honor. Por tanto, las sentencias apuntadas en el anterior epígrafe se refieren principalmente, aunque no exclusivamente, a esta cuestión; por ello dedicamos este epígrafe a los otros dos derechos: a la intimidad personal y familiar y a la propia imagen.

Respecto al derecho a la intimidad y a la propia imagen, destaca la conocida Sentencia 231/1988, de 2 de diciembre, caso Francisco Rivera. El caso parte de la publicación por Prographic de las imágenes de la mortal cogida sufrida por el torero, que llevaron a su entonces mujer Isabel Pantoja, a pedir la anulación, como así fue, de la STS de 28 de octubre de 1986. El Tribunal Constitucional señala en su fundamento jurídico $6 .^{\circ}$ que «se trata pues, de imágenes de las que, con seguridad, puede inferirse, dentro de las pautas de nuestra cultura, que inciden negativamente, causando dolor y angustia en los familiares cercanos del fallecido. No cabe pues dudar de que las imágenes en cuestión, y según lo arriba dicho, inciden en la intimidad personal y familiar de la hoy recurrente, entonces esposa, y hoy viuda, del desaparecido señor Rivera». Las escenas reproducidas graban la muerte del torero en la enfermería de la plaza, que el Tribunal Constitucional estima violan el derecho a la intimidad personal y familiar del torero y su viuda y, por lo tanto, han de considerarse como una intromisión ilegítima. Por último, en el fundamento jurídico $3 .^{\circ}$ se nos recuerda que estos dos derechos derivan de la dignidad de la persona (art. 10.1 CE), son derechos personalísimos y por tanto ligados a la existencia del individuo.

\subsection{El derecho al olvido como limite al derecho a la información}

El derecho al olvido es una concreción de los derechos personalísimos en el ámbito de la nueva realidad tecnológica que supone el mundo de internet. En la red quedan almacenadas noticias sobre nuestra persona que pueden afectarnos y perjudicarnos y que han quedado obsoletas y sin interés público para el internauta o ciudadano. En estos últimos años se ha planteado el derecho al olvido como una especificidad del derecho al honor y a la intimidad, donde una persona quiere limitar o suprimir el conocimiento que sobre ella existe en la red. Estamos por tanto ante un nuevo conflicto entre el derecho a la información del 
usuario y el derecho al honor y a la intimidad del afectado en la realidad desbordante de internet.

En este caso no vamos a exponer ninguna sentencia de nuestro poder corrector, sino que nos centraremos en una Sentencia del Tribunal de Justicia de la Unión Europea y en otra de nuestro Tribunal Supremo.

En la Sentencia (C-131/12) asunto Mario Costeja, de 13 de mayo de 2014, el Tribunal de Justicia de la Unión Europea aclara una cuestión prejudicial de carácter interpretativo de la Audiencia Nacional española sobre la Directiva 95/46/CE de protección de datos personales ${ }^{34}$. El 5 de mayo de 2010 el ciudadano Mario Costeja presenta una reclamación ante la Agencia Española de Protección de Datos (AEPD) contra La Vanguardia y Google Spain y Google Inc. El motivo es porque cuando cualquier internauta ponía su nombre en el motor de búsqueda de Google, aparecían dos páginas del citado periódico con un anuncio de subasta de inmuebles de su propiedad en el año 1998 por embargo motivado por impagos a la Seguridad Social; deudas por cierto ya saldadas. La AEPD en julio de 2010 da la razón a La Vanguardia, pues hacia su trabajo y la información en su día era correcta, pero obliga a Google a borrar los datos del buscador. Google se niega y plantea el caso a la Audiencia Nacional, que tiene dudas a la hora de interpretar la citada Directiva, y por ello consulta al TJUE con una cuestión prejudicial.

A los efectos que nos interesa, la Sentencia del TJUE aclara algunas dudas, ciertamente, no todas. El Tribunal no objeta nada a la publicación del medio, La Vanguardia en este caso, hizo lo que debía. La información era correcta y en su día de interés de cara a la subasta. Sí se cuestiona el Tribunal, si desaparecido el interés o la finalidad de la publicación, tiene sentido mantener la misma si perjudica al afectado. El propio TEDH se pregunta si el deber de diligencia se da solo en el momento de la publicación o afecta también al mantenimiento de la misma en la hemeroteca digital del medio ${ }^{35}$. Por lo demás, no hay que olvidar que el poder de invasión o impacto de la hemeroteca de un periódico y de un buscador como Google, es verdaderamente abismal.

En cualquier caso, el TJUE obliga a Google a ponderar y estudiar supuesto por supuesto, dejando claro que el derecho a la privacidad del titular de los datos está por encima del interés económico del gestor del motor de búsqueda y del derecho del internauta de acceso a la información. Tendrá que valorar el interés de la noticia para mantenerla con el perjuicio que se le produce al protagonista

34 No olvidar igualmente el artículo 8 de la Carta de Derechos Fundamentales de la UE que regula el derecho de toda persona a la protección de datos de carácter personal.

35 STEDH Wergrzynowski y Smolozewski vs. Polonía, de 16 de julio de 2013. 
de la noticia. Al respecto Google, ha creado un comité de expertos que estudia las miles de peticiones de derecho al olvido que recibe.

Si la Sentencia estudiada del caso Mario Costeja pone las primeras bases para delimitar y dotar de contenido más preciso al derecho al olvido, la Sentencia del Tribunal Supremo de 19 de octubre de 2015 va a dar un claro paso hacia delante.

Como síntesis podemos avanzar que el Tribunal Supremo rechaza alterar la hemeroteca por el derecho al olvido, aunque sí obliga a los periódicos a evitar que la información pueda encontrarse en los buscadores. En cierta medida, el Tribunal no permite que los ciudadanos se puedan crear un pasado a su medida en internet. El supuesto que enjuicia el Tribunal es una noticia de El País de 1985 de dos personas detenidas por tráfico de drogas. En 2009, pasados más de 20 años y con la condena cumplida y cancelados sus antecedentes penales, comprueban que introduciendo sus nombres en Google o Yahoo, el enlace a la noticia aparecía de los primeros. Los afectados van a los Tribunales y el Tribunal Supremo, en última instancia, concluye con las siguientes ideas: el derecho a la intimidad y al honor, base del derecho al olvido, prevalece sobre el derecho a la información de los internautas cuando la noticia es obsoleta y gravemente perjudicial para el afectado, que además no es persona pública o la misma carece de interés histórico. En este caso la información debe desaparecer de los buscadores de internet, como Google, Yahoo o Bing.

El procedimiento para ejercer el derecho al olvido es dirigirse a los gestores de los buscadores, si no está de acuerdo con la respuesta, si la hay, dirigirse a la Agencia Española de Protección de Datos y si no está de acuerdo, en última instancia, acudir a los Tribunales, pues estamos ante un derecho fundamental, incluido en el artículo 8 de la Carta de Derechos Fundamentales de la UE y en el artículo 18.4 de nuestra Constitución.

\subsection{Uso de la cámara oculta}

La STC 12/2012, de 30 de enero, ha venido a disipar cualquier duda sobre la negativa de nuestro más alto Tribunal a la hora de permitir la emisión de programas televisivos en los que los periodistas hayan utilizado una cámara oculta para la grabación de los mismos, independientemente de la relevancia pública de la información. Así, en su fundamento jurídico $6 .^{\circ}$ señala «la especial capacidad intrusiva del medio específico utilizado para obtener y dejar registradas las imágenes y la voz de una persona. [...] el carácter oculto que caracteriza a la técnica de investigación periodística llamada «cámara oculta» impide que la persona que está siendo grabada pueda ejercer su legítimo poder de exclusión 
frente a dicha grabación [...], pues el contexto secreto y clandestino se mantiene hasta el mismo momento de la emisión. [... L La ausencia de conocimiento y, por tanto, de consentimiento de la persona fotografiada respecto a la intromisión en su vida privada es un factor decisivo en la necesaria ponderación de los derechos en conflicto, como subraya el Tribunal Europeo de Derechos Humanos (SSTEDH de 24 de junio de 2004, Von Hannover c. Alemania, y de 10 de mayo de 2011, Mosley c. Reino Unido)».

Y para fortalecer la argumentación en contra de su uso, en su fundamento jurídico $7 .^{\circ}$ apunta que «aun cuando la información hubiera sido de relevancia pública, los términos en que se obtuvo y registró, mediante el uso de una cámara oculta, constituyen en todo caso una ilegítima intromisión en los derechos fundamentales a la intimidad personal y a la propia imagen».

\subsection{Regulación jurídica de la radio y la televisión}

El Gobierno del Presidente Suárez, a través del Estatuto de la Radio y la Televisión de 1980, opta por considerar el servicio de radio y televisión como un servicio público esencial ${ }^{36}$. No fueron pocos los que vieron esta norma como un claro límite a la libertad informativa consagrado en el artículo 20.1.d) CE. En este sentido, el Tribunal Constitucional publica una Sentencia decisiva para el concepto de la televisión pública o privada en España, la conocida STC 12/1982, de 31 de marzo, caso Antena TV. El problema básico que plantea la demanda, según el Fiscal General del Estado, es el de determinar en qué medida la Ley 4/1980, de 10 de enero, Estatuto de la Radio y la Televisión, se opone a la televisión privada, y estima que la declaración del artículo 1.2 de dicha Ley, según el cual «la radiodifusión y la televisión son servicios públicos esenciales cuya titularidad corresponde al Estado», no queda suficientemente cubierta por el artículo $128 \mathrm{CE}$, en el que se establece que «mediante Ley se podrán reservar al sector público recursos o servicios esenciales». La clave la vamos a encontrar en el fundamento jurídico $4 .^{\circ}$ de la Sentencia, al afirmar el Tribunal Constitucional que «la configuración de la televisión como servicio público, aunque no sea una afirmación necesaria en nuestro orden jurídico-político, se encuentra dentro de los poderes del legislador». Dicho con otras palabras más adelante por el propio Tribunal, «adoptar el sistema de gestión indirecta del servicio público

36 El resto de Presidentes optaron igualmente por el mismo criterio: El Presidente González (PSOE), Aznar (PP), Zapatero (PSOE) y Rajoy (PP). Parece que en esta cuestión, independientemente de la muy distinta ideología de los Presidentes — tanto de la UCD, como del PSOE o del PP_, han estado todos de acuerdo. 
requiere una decisión del legislador y un desarrollo legislativo que este Tribunal no puede suplir». Por tanto, el Tribunal Constitucional nos viene a indicar que, con lo regulado en la Constitución Española, caben los dos tipos de televisión, esto es, pública o privada, y que esta elección es potestad del Legislador hacerla.

\subsection{Cláusula de conciencia}

Jurisprudencialmente es de interés la STC 225/2002, de 9 de diciembre, por la que no se obliga al redactor del diario YA, Francisco Escobar Jiménez, a permanecer en su puesto de trabajo hasta la declaración judicial constitutiva de la extinción del contrato de trabajo, por cambio notable en la línea editorial. Admitía por tanto nuestro Tribunal la cuestión relativa a la posibilidad de una dimisión previa en base a la cláusula de conciencia. Básicamente porque lo contrario, supondría, según indica el propio Tribunal: «excluir la posibilidad del cese anticipado en la prestación laboral, es decir, obligar al profesional, supuesto el cambio sustancial en la línea ideológica del medio de comunicación, a permanecer en éste hasta que se produzca la resolución judicial extintiva, implica ya aceptar la vulneración del derecho fundamental, siquiera sea con carácter transitorio — durante el desarrollo del proceso_- lo que resulta constitucionalmente inadmisible — recuérdese que en el caso que se examina el cambio de la línea ideológica del periódico podía "dar lugar a una situación incómoda y angustiosa” .

\subsection{Derecho de rectificación}

A pesar de que, a diferencia de otros aspectos del derecho a la información, respecto del derecho de rectificación sí existe regulación legal, no es menor la jurisprudencia ${ }^{37}$ del Tribunal Constitucional que ha ido perfilando su contenido desde el año 1983, un año antes de la aprobación de la propia Ley Orgánica 2/1984, de 26 de marzo, sobre el derecho de rectificación. En este sentido, la STC 51/2007, de 12 de marzo, en su fundamento jurídico 8. ${ }^{\circ}$ nos describe esta propia evolución jurisprudencial en los siguientes términos: «Comenzando por recordar nuestra doctrina referente al derecho de rectificación puede recordarse que ya en la STC 35/1983, de 11 de mayo, FJ 4, se hablaba del «carácter puramente instrumental» del mismo «en cuanto su finalidad se agota en la rectifica-

37 Básicamente destacan la STC 35/1983, de 11 de mayo; 168/1986, de 22 de diciembre; 40/1992, de 30 de marzo; 51/2007, de 12 de marzo y 99/2011, de 20 de junio, que sintetizaremos en este trabajo. 
ción de informaciones publicadas»; y en la STC 168/1986, de 22 de diciembre, FJ 4, se afirmaba que «el derecho de rectificación es solo un medio del que dispone la persona aludida para prevenir o evitar el perjuicio que una determinada información pueda irrogarle en su honor». Precisamos también en la STC 40/1992, de 30 de marzo, FJ 2, que «si bien el derecho a la rectificación de la información no suplanta, ni, por tanto, inhabilita ya, por innecesaria, la debida protección al derecho del honor, sí la atenúa, pues constituye el mecanismo idóneo para reparar lo que solo por omisión de los hechos relatados pudiera constituir intromisión en el derecho al honor imputable a quien sirve de soporte o vehículo para la difusión pública de tales hechos».

Por último y en relación con la labor investigadora y de cotejo de la información de los tribunales que aplican el derecho de rectificación y el alcance de dicho procedimiento, es reveladora la STC 99/2011, de 20 de junio, especialmente en su fundamento jurídico $3 .^{\circ}$ : «el ordenamiento jurídico ofrece las pertinentes acciones penales y civiles cuyo ejercicio en el marco de los respectivos procedimientos constituyen la vía adecuada para la investigación de la verdad de los hechos publicados o difundidos. A través de tales procedimientos podrá dilucidarse la certeza o la falsedad de los hechos o las informaciones, con los efectos propios de la cosa juzgada». Para más adelante marcar el verdadero sentido del procedimiento regulado en la LO 2/1984: «la sumariedad del procedimiento verbal, de la que es buena muestra que solo se admitan las pruebas pertinentes que puedan practicarse en el acto [art. 6 b)], exime sin duda al Juzgador de una indagación completa tanto de la veracidad de los hechos difundidos o publicados como de la que concierne a los contenidos en la rectificación, de lo que se deduce que, en aplicación de dicha Ley, puede ciertamente imponerse la difusión de un escrito de réplica o rectificación que posteriormente pudiera revelarse no ajustado a la verdad».

\subsection{Veracidad informativa y relevancia pública de la noticia}

El fundamento jurídico $4 .^{\circ}$ de la STC 123/1993, de 19 de abril, nos señala su contenido y evolución jurisprudencial en los siguientes términos: «la veracidad de la información, este Tribunal Constitucional ha establecido una consolidada doctrina (SSTC 6/1988, 171/1990, 219/1992 y 240/1992, entre otras), que sintetizamos, reiterando nuevamente que la regla de la veracidad no exige que los hechos o expresiones contenidos en la información sean rigurosamente verdaderos, puesto que las afirmaciones erróneas o equivocadas son inevitables en un debate libre, sino que impone al comunicador un específico deber de diligencia en la comprobación razonable de la veracidad en el sentido de que la infor- 
mación rectamente obtenida y razonablemente contrastada es digna de protección, aunque su total exactitud sea controvertible o se incurra en errores circunstanciales que no afecten a la esencia de lo informado, debiéndose, por el contrario, negar la garantía constitucional a quienes actúen con menosprecio de la veracidad o falsedad de lo comunicado, transmitiendo, de manera negligente o irresponsable, como hechos, simples rumores carentes de toda constatación o meras opiniones gratuitas que, realmente, son insinuaciones insidiosas» ${ }^{38}$.

La veracidad es un requisito del legítimo ejercicio del derecho a la información que viene contemplado en el propio Texto constitucional, al señalar el artículo 20.1.d) el derecho «a comunicar y recibir libremente información veraz...». Sin embargo, el Tribunal Constitucional a través de sus sentencias va a exigir otro requisito para que la información sea protegida. En cierta medida perfila el objeto del derecho a la información, pues no solo versa sobre hechos veraces sino que también deben ser hechos noticiables. Así nos lo indica en la Sentencia 107/1988 al afirmar que «la libertad del artículo 20.1.d) tiene por objeto el comunicar y recibir libremente información sobre hechos o, tal vez, más restringidamente, sobre hechos que puedan considerarse noticiables». Qué debemos entender por noticiable se perfila en sentencias como la 171/1990 al indicar que «el efecto legitimador del derecho a la información que se deriva de su valor preferente requiere, por consiguiente, no solo que la información sea veraz — requisito necesario directamente exigido por la propia Constitución, pero no suficiente-, sino que la información tenga relevancia pública, lo cual conlleva que la información veraz que carece de ella no merece la especial protección jurisdiccional».

Estamos por tanto ante una exigencia o requisito de creación jurisprudencial, que define o perfila el contenido del derecho, al concretarlo en aquellos hechos veraces que sean noticiables o tengan relevancia pública, esto es, noticias de interés para el público, que afecten a su vida pública o social, no se protegen por tanto, aquellas noticias, aunque sean veraces, que carecen de interés para la vida pública o en común de los ciudadanos.

${ }^{38}$ En una línea similar, la STC 320/1994 (fundamento jurídico 3.º declaró que la veracidad de lo que se informa «no va dirigida tanto a la exigencia de una rigurosa y total exactitud en el contenido de la información, sino a negar la protección constitucional a los que, defraudando el derecho de todos a recibir información veraz, transmiten como hechos verdaderos, bien simples rumores, carentes de toda constatación, bien meras invenciones o insinuaciones, sin comprobar su veracidad mediante las oportunas averiguaciones propias de un profesional diligente, aunque su total exactitud pueda ser controvertida o se incurra en errores circunstanciales que no afecten a la esencia de lo informado». 


\subsection{Especial referencia al TEDH}

Es poco discutible el papel director que en materia de derechos humanos ha ejercido el Tribunal Europeo de Derechos Humanos (TEDH) en aplicación del Convenio Europeo para la protección de los derechos humanos y de las libertades fundamentales de 1950. Las principales instituciones europeas así lo reconocen, tanto a nivel institucional, como legislativo y muy especialmente jurisprudencial. Es bastante frecuente que los diferentes Tribunales constitucionales del continente europeo, incluso fuera de él, tengan presentes sus diferentes sentencias. En este sentido el Tribunal Constitucional español y sus diversas resoluciones han seguido en numerosas ocasiones las pautas jurisprudenciales marcadas por el TEDH, por ello, estimamos pertinente dedicar un breve epígrafe a, lo que a nuestro entender, han sido las dos sentencias más influyentes en materia de derecho a la información del TEDH en estas cuatro últimas décadas que estamos analizando. No siendo esta selección fácil, pues son muy numerosas las resoluciones $^{39}$ que el TEDH ha publicado en interpretación del artículo 10 del Convenio, que regula aquel derecho, nos atreveríamos a decantarnos por la Sentencia de 8 de julio de 1986, caso Lingens vs. Austria y la Sentencia de 24 de junio de 2004, caso Von Hannover vs. Alemania, más conocida como Sentencia sobre Carolina de Mónaco.

Destacamos la Sentencia Lingens de 1986 por su incidencia en la consolidación de la dimensión institucional o doble carácter del derecho a la información sobre los derechos personalísimos o derechos del ámbito de la privacidad, dándole por tanto al primero un plus de preferencia o prevalencia sobre los segundos. Es verdad que la Sentencia de 7 de diciembre de 1976, caso Handyside vs. Reino Unido ya había iniciado la importancia que la libertad de información tiene para una verdadera sociedad democrática; sin embargo, el paso que da en 1986 el TEDH es que «cuando afecta a las controversias políticas hay un plus de especial protección sobre la ya especial protección que tiene la libertad de expresión» ${ }^{40}$. El hecho pues de la relevancia pública de la noticia, es determinante. Así lo indica el propio TEDH en el apartado 42 de la Sentencia Lingens: «la libertad

39 Sirva como botón de muestra algunas de las más recientes: Sentencia 21 de febrero de 2017 , caso Paulina Rubio vs. España; Sentencia de 11 de octubre de 2016, caso Cano Moya vs. España; Sentencia de 14 de junio de 2016, caso Jiménez Losantos vs. España; Sentencia de 23 de abril de 2015, caso Morice vs. Francia; Sentencia de 15 de octubre de 2015, caso Perincek vs. Suiza; Sentencia de 20 de octubre de 2015, caso Pentikäinen vs. Finlandia; Sentencia de 10 de noviembre de 2015, caso Couderc et Hachette Filipacchi Associés vs. Francia.

40 Ver David Ortega Gutiérrez, Derecho a la información versus derecho al honor, Madrid, CEPC, 1999 , p. 88. 
de las controversias políticas pertenece al corazón mismo del concepto de sociedad democrática que inspira el Convenio».

En la otra Sentencia señalada, la Princesa Carolina denuncia ante el TEDH a Alemania solicitando la protección real y efectiva de su vida privada en relación con unas fotografías tomadas a la Princesa en compañía de otras personas en momentos de su vida cotidiana en la vía pública. La clave está en que mientras el Tribunal Constitucional alemán sentenciaba que la Princesa, dada su dimensión de figura pública, debía tolerar esas instantáneas, a favor de la libertad de prensa y el interés legítimo del sujeto universal o público de saber cómo se comporta, al TEDH le parece imposible aceptar tal planteamiento, ya que las fotografías en sí nada aportan a un debate de interés público ${ }^{41}$ y su captación y difusión no fueron consentidas.

\section{DEONTOLOGÍA PERIODÍSTICA Y MECANISMOS DE AUTORREGULACIÓN}

Una de las principales funciones del periodismo es servir de control al poder, especialmente, al poder político y dentro de éste, al poder ejecutivo o Gobierno; por ello, puede resultar poco aconsejable que el control sobre la profesión periodística se centre excesivamente en las normas jurídicas impulsadas principalmente por el Gobierno, a través del Parlamento. Por tanto, en materia de deontología periodística se imponen las medidas de autocontrol o autorregulación. Esto es, son los propios profesionales los que se dan sus propias normas éticas para una buena praxis de la profesión periodística.

En este sentido, en estas cuatro décadas, destacarían los siguientes Códigos deontológicos. En primer lugar el Código Deontológico de los periodistas de Cataluña, aprobado el 1 de noviembre de 1992 en un Congreso organizado por el Colegio Oficial de Periodistas de Cataluña. Es este texto el que abre camino en España. Tiene 12 puntos: 1 . Distinguir hechos y opiniones, 2. Difundir solo información fundamentada, 3. Rectificar con diligencia, 4. Utilizar medios dignos para obtener información o imágenes, 5. Respetar el off the record, 6. Reconocer el derecho

41 Más extensamente ver Bruno García-Dobarco González: «La vida privada de los personajes públicos: STEDH Von Hannover c. Alemania de 24 de junio de 2004», en Revista Europea de Derechos Fundamentales, n. ${ }^{\circ}$ 4, 2004, pp. 177-190 y Jesús María SANTOS Vijande: «La captación y difusión no consentidas de la imagen de personas públicas en momentos de su vida privada: comentario a la STEDH (sección 3. ${ }^{\text {) }}$ ) de 24 de junio de 2004 (asunto von Hannover —Princesa Carolina de Mónaco- contra Alemania», en Repertorio Aranzadi del Tribunal Constitucional, n. ${ }^{\circ} 3$, 2004, pp. 2953-2970. 
a no responder, 7. No aceptar gratificaciones, 8. No utilizar en beneficio propio información privilegiada, 9. Respetar el derecho a la intimidad y a la propia imagen, 10. Observar el principio de presunción de inocencia, 11. Tratar con especial cuidado información sobre menores, y 12. Actuar con responsabilidad en informaciones que puedan suscitar discriminación. De su aplicación y cumplimiento se encarga el Consell de la Informació, creado en diciembre de 1997 por el propio Colegio Oficial.

En segundo lugar — y hoy por hoy el texto más influyente y relevante en España- está el Código Deontológico de la Federación de Asociaciones de Periodistas de Espa$\tilde{n} a$ (FAPE) aprobado en la Asamblea ordinaria celebrada en Sevilla el 27 de noviembre de 1993. Tiene 20 puntos divididos entre principios generales, estatuto y principios de actuación. Sus contenidos esenciales son el respeto a la verdad, el principio de la libertad de investigar y difundir con honestidad, respetar el derecho a la propia intimidad e imagen, con especial énfasis en el caso de los menores, defensa del secreto profesional y la cláusula de conciencia, el deber de contrastar la fuente y ofrecer al afectado dar su versión, corregir el error con rapidez, respetar el off the record y distinguir información de publicidad, entre otras cuestiones.

En el ámbito europeo destaca el Código Europeo de Deontología del Periodismo, aprobado por el Consejo de Europa en Estrasburgo el 1 de julio de 1993. Tiene 38 puntos y 4 recomendaciones al Comité de ministros. Posiblemente sea el Código más completo y realista de los apuntados. Tiene presente a los medios de comunicación y a las empresas informativas, en las que se distinguen editores, propietarios y periodistas. En su punto 11 se las define como «empresas especiales socioeconómicas, cuyos objetivos empresariales deben quedar limitados por las condiciones que deben hacer posible la prestación de un derecho fundamental». En el punto 12 defiende «el conocimiento claro de los ciudadanos sobre la identidad de los propietarios y del nivel de su participación económica en los medios de comunicación». Este punto me parece verdaderamente relevante y es uno de los «debe» de algunas de las empresas informativas españolas, la falta de transparencia de sus consejos de administración y resultados de sus cuentas. Veamos cuál es la realidad.

Si consultamos las páginas web de los principales grupos de comunicación de España, esto es: Prisa ${ }^{42}$, Vocento ${ }^{43}$, RCS Mediagroup ${ }^{44}$, Plane-

42 Respecto a su consejo de administración: http://www.prisa.com/es/info/consejo-de-administracion-y-comisiones-del-consejo.

En relación con sus cuentas: http://www.prisa.com/es/datos/cuentas-anuales.

43 En relación a sus cuentas: http://www.vocento.com/vocentocom/wp-content/uploads/ sites/5/2017/05/Informe_de_Resultados_1T17_DEF.pdf.

44 Respecto a su consejo de administración: http://www.rcsmediagroup.it/pagine/governance/organi-societari/cda/. 
$\mathrm{ta}^{45}$, Grupo Godo ${ }^{46}$ y Mediaset ${ }^{47}$; nos encontramos con la siguiente realidad. La composición de sus consejos de administración, con nombres, apellidos y trayectoria profesional es fácilmente accesible en los grupos Prisa, RCS Mediagroup, Grupo Godo y Mediaset. En los grupos Vocento y Planeta no la hemos encontrado o, al menos, su acceso no es fácil, en el caso de que la información esté. En relación con la información económica, de accionistas, inversores y capital social: Prisa, Vocento, RCS Mediagroup y Mediaset ofrecen esa información con bastante detalle. El resto de grupos, Planeta y Godo, no hemos logrado localizarla. Por tanto, podemos concluir que Prisa, RCS y Mediaset aparecen como los grupos informativos con una información más clara y accesible para los ciudadanos.

\section{CONCLUSIONES Y CUESTIONES PENDIENTES}

Después del análisis normativo y jurisprudencial realizado sobre los cuarenta años de desarrollo del derecho a la información, podemos apuntar las siguientes conclusiones.

En primer lugar, el tratamiento normativo y jurisprudencial ha sido, desde una perspectiva global y genérica, suficiente, en una línea similar o parecida a la de los países de nuestro entorno europeo. Se puede afirmar que los españoles hemos podido disfrutar en estas cuatro décadas de un derecho fundamental a la información que nos ha permitido, en líneas generales y con algunos límites, conocer los principales sucesos y acontecimientos de nuestra vida pública.

En segundo lugar, estimamos que en materia de transparencia y acceso a la información pública es donde más ha fallado el legislador español. Ha legislado tarde y no con demasiada responsabilidad y ambición para avanzar en la lucha contra uno de los principales problemas de nuestra vida pública: la corrupción.

En tercer lugar, lógicamente no ha sido una regulación y tratamiento doctrinal sobresaliente, por ello, a continuación expondremos aquellas cuestiones que, según nuestro criterio, deben mejorar para poder tener un derecho a la información más eficaz y pleno.

En relación a sus cuentas: http://www.rcsmediagroup.it/wp-content/uploads/doc/2017-05/ BILANCIO-E-RELAZIONE-AL-31-DICEMBRE-2016.pdf.

45 Página web: http://www.planeta.es/es/el-grupo-planeta.

46 En relación a su consejo de administración: http://www.grupogodo.com/consejo-deadministracion/.

47 Respecto a su consejo de administración: http://www.mediaset.es/inversores/es/consejode-administracion.html.

En relación a sus cuentas: http://www.mediaset.es/inversores/es/informacion-financiera.html. 
Primera. Dar cumplimiento al mandato del poder constituyente del artículo 20.1.d) y regular el derecho al secreto profesional. Ocasiones y propuestas ha habido, ha faltado voluntad política. Entiendo que en esa ley, que tendrá que ser orgánica, debiera de fijarse quién es periodista en España, para evitar equívocos sobre quién puede disfrutar precisamente del derecho al secreto profesional o a la cláusula de conciencia.

Segunda. Establecer los mecanismos oportunos para despolitizar la televisión pública en España, tanto a nivel nacional como autonómico. Concretamente, podría empezarse por la elección del Presidente y de los miembros del Consejo de Administración de la Corporación de RTVE, que debieran de elegirse por mayoría de dos tercios del Congreso de los Diputados y no por mayoría absoluta, como en la actualidad.

En la presente Legislatura hay iniciativas al respecto, pero con fortuna dispar, por el momento. Así, el 23 de junio de 2017 el Congreso de los Diputados aprobó prácticamente por unanimidad ${ }^{48}$ volver a la mayoría de dos tercios para la elección del Presidente y de los consejeros, entre otras cuestiones ${ }^{49}$. Parecía que se iniciaba un buen camino guiado por la imparcialidad, independencia y pluralismo en la cabeza de nuestra RTVE. Sin embargo, el 5 de septiembre de ese año, un acuerdo PP-PSOE en el Senado apoya la enmienda del PP para que con mayoría de $3 / 5^{50}$ en segunda votación - PP y PSOE la superan en el Congreso con 222 diputadospuedan elegir al Presidente y consejeros de la Corporación, por lo que se malogra la deseada despolitización de la dirección de nuestra radio y televisión públicas.

Tercera. En relación con el punto anterior y desde un enfoque global, falta un modelo consensuado y ambicioso de una prestigiosa televisión pública, más allá de cortoplacistas criterios de rédito político. En este sentido, los diferentes grupos parlamentarios mayoritarios no han estado a la altura en estas cuatro décadas de vida de nuestra Constitución.

Cuarta. En materia de autorregulación, los consejos de medios audiovisuales o similares deben regirse por la independencia y el prestigio profesional, además del necesario pluralismo en su composición. En líneas generales, se deben potenciar los diferentes mecanismos de autorregulación apuntados, para lograr un mayor nivel ético y deontológico de la práctica del periodismo.

Quinta. La Ley 19/2013, de 9 de diciembre, de transparencia, es excesiva en sus límites (art. 14), sobran algunos como los «intereses económicos y comer-

48 Tan solo hubo una abstención, ningún voto en contra y 345 votos a favor.

49 Ver http://www.rtve.es/noticias/20170622/congreso-aprueba-rtve-tenga-nuevo-presidente-consejo-tres-meses-concurso-publico/1568664.shtml.

50 Se precisan 210 diputados en el Congreso de los Diputados. 
ciales» o «la política económica y monetaria». Igualmente, el procedimiento de acceso a la información pública es verdaderamente complejo y disuasorio, tal y como en su día afirmó la Defensora del Pueblo. Habría que simplificarlo para hacerlo realmente viable. Por último, el derecho de acceso a la información pública debe considerarse como un derecho fundamental y parte del contenido del artículo 20.1.d) CE.

Sexta. No es de recibo que algunos órganos constitucionales y organismos públicos no cumplan con la citada Ley 19/2013, tal y como ha señalado recientemente el Informe de marzo de 2017 del Consejo de Transparencia. Algún tipo de medida o responsabilidad debiera de tomarse al respecto si verdaderamente queremos avanzar en materia tan relevante.

Séptima. Habría que actualizar la añeja Ley de Secreto Oficiales de 1968, especialmente en la desclasificación de materias que pueden ser secretas o reservadas con carácter indefinido, algo verdaderamente excepcional en el ámbito de la Unión Europea.

Octava. Sería conveniente que la Ley Orgánica 1/1982, de 5 de mayo, de protección civil del derecho al honor, a la intimidad personal y familiar y a la propia imagen, se adapte a la extensa y consolidada jurisprudencia del Tribunal Constitucional y regule de manera autónoma e individualizada cada uno de estos tres derechos.

Novena. Hay que modificar el artículo 36 de la Ley de Seguridad Ciudadana del año 2015, que limita en exceso el derecho a la información en relación con la actividad de los cuerpos y fuerzas de seguridad del Estado.

Décima. Ninguna mención hemos hecho al mundo de las redes sociales, que daría para otro estudio, apuntar sucintamente el necesario equilibrio entre información, rigor y responsabilidad en este complicado ámbito de comunicación a escala global.

Title:

The Right to Information: Balance and outstanding issues

\section{Summary:}

1. Introduction. 2. Normative development. 2.1 Laws that have directly developed the right to information. 2.2 Laws indirectly related to the right to information. 3. Jurisprudential developments. 
3.1 Institutional dimension or double character of the right to information, especially against the right to honor. 3.2. Faced with the right to privacy and self-image. 3.3 The right to be forgotten as a limit to the right to information. 3.4 Using the Hidden Camera. 3.5 Legal regulation of radio and television. 3.6 Conscience clause. 3.7 Right to rectification. 3.8 Veracity informative and public relevance of the news. 3.9 Special reference to the ECHR. 4. Journalistic ethics and self-regulation mechanisms. 5. Conclusions and outstanding issues.

\title{
Resumen:
}

Se analiza el derecho a la información y su evolución en estos 40 años de vida de nuestra Constitución de 1978. Primero se estudian aquellas normas jurídicas que han desarrollado directamente este derecho para después ver aquéllas que lo han hecho de manera indirecta o colateral. En segundo lugar apuntamos la evolución jurisprudencial de los temas más relevantes del derecho a la información, especialmente respecto del contenido y límites al mismo. En un tercer apartado se aborda la evolución de la deontología en materia de periodismo. Concluimos con una serie de temas y problemas del derecho a la información que aún siguen pendientes.

\begin{abstract}
:
It analyzes the right to information and its evolution in these 40 years of life of our Constitution of 1978. First we study those legal norms that have directly developed this right to later see those who have done so indirectly or collateral. Secondly, we point out the jurisprudential evolution of the most relevant issues of the right to information, especially regarding the content and limits to it. A third section deals with the evolution of deontology in journalism. We conclude with a series of issues and problems of the right to information that are still pending.
\end{abstract}

\section{Palabras clave:}

Derecho a la información, derecho a la comunicación, evolución jurisprudencial.

Key words:

Right to information, right to communication, jurisprudential evolution. 